\title{
Mechanical and microscopic properties of API G cement after exposure to supercritical $\mathrm{CO}_{2}$
}

\author{
Chun-Chih Kuo ${ }^{1, *}$, Chein-Lee Wang ${ }^{2}$, and Hsing-I Hsiang ${ }^{2}$ \\ ${ }^{1}$ Department of Civil Engineering, National Taiwan University, Taipei City, Taiwan \\ ${ }^{2}$ Department of Resources Engineering, National Cheng Kung University, Tainan City, Taiwan
}

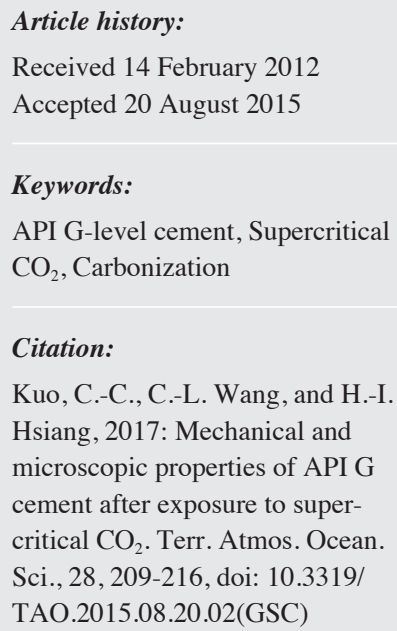

\begin{abstract}
An experiment on API G-level (American Petroleum Institute) cement is conducted after curing under a supercritical carbon dioxide environment. Cement paste is prepared first to generate a uniaxial compressive specimen, after which the specimen is exposed to the supercritical carbon dioxide environment (temperature $=70^{\circ} \mathrm{C}$; pressure $=20 \mathrm{MPa}$ ) for curing at different numbers of days ( $7-84$ days). The physical and chemical changes in the cement are subsequently simulated at $1500-2000 \mathrm{~m}$ below the injection well during $\mathrm{CO}_{2}$ sequestration. Results show that the uniaxial compressive strength of the specimen decreases as the number of curing days increases, indicating that the specimen sustains considerable damage when cured under humid environments. This result also implies a declining trend in the longitudinal and transverse waves of the cured specimen. Based on the material analytical results we determine that carbon dioxide reacts with the calcium hydroxide, water and calcium silicate in the cement. The carbon dioxide is then converted into calcium carbonate, resulting in different degrees of carbonization depending on the number of curing days.
\end{abstract}

\section{INTRODUCTION}

Carbon capture and storage is one of the technologies that has drawn increasing attention from the scientific community in recent years. The sequestration of carbon dioxide into geological structures, as well as the use of man-made sealing, is regarded as a developmental technology. Geological sequestration features large volumes of sequestered carbon dioxide, requiring long-term safety and geographical universality (e.g., Iding and Ringrose 2010; Gislason et al. 2010).

The geological sequestration of carbon dioxide is subject to leakage caused by a number of factors, including the mechanical structure of injection wells, geological defects, well degradation and other potential risks (Viswanathan et al. 2008).

Cement has been regarded as the primary well strengthening material for a long time and its durability and low permeability are features required by oil (gas) wells (Carey 2007). Sampling of existing sequestration sites confirms that carbon dioxide injection (secondary oil production or geological sequestration) enables the dissolution of

\footnotetext{
* Corresponding author

E-mail:chunchih@ntu.edu.tw
}

carbon dioxide in water and formation of carbonic acid (e.g., Barlet-Gouédard et al. 2007; Rimmelé et al. 2008; Liteanu et al. 2009), thereby resulting in the long-term degradation of cement mechanical properties and increased risk of $\mathrm{CO}_{2}$ leakage (e.g., Benge 2009; Fabbri et al. 2009; Liteanu et al. 2009; Wigand et al. 2009).

We conducted an experiment on API G-level cement after curing under a supercritical carbon dioxide environment. Cement paste is first prepared to generate an uniaxial compressive specimen, after which the specimen is exposed to a supercritical carbon dioxide environment (temperature $=70^{\circ} \mathrm{C}$; pressure $=20 \mathrm{MPa}$ ) for curing at different numbers of days ( 7 - 84 days). The physical and chemical changes in the cement are simulated at $1500-2000 \mathrm{~m}$ below the injection well during $\mathrm{CO}_{2}$ sequestration.

\section{EXPERIMENTAL METHOD AND EQUIPMENT}

\subsection{Experimental Method}

API G-level cement is chosen as the experimental material (dynamic elasticity coefficient $\mathrm{E}_{\mathrm{d}}=5.664 \mathrm{GPa}$; Poisson's ratio $=0.277$; compressive strength $=6.13 \mathrm{MPa}$ ) and 
cylindrical specimen $($ diameter $=5 \mathrm{~cm}$; height $=10 \mathrm{~cm})$. The specimen is prepared according to API specifications (API 1985). The prepared specimens are placed in a $\mathrm{Ca}(\mathrm{OH})_{2}$ solution for 28-day curing, carried out in a supercritical reactor (Fig. 1).

\subsection{Experimental Equipment}

A supercritical carbon dioxide reactor is used to cure API G-level cement for different numbers of days. The curing is carried out under a supercritical carbon dioxide environment (temperature $=70^{\circ} \mathrm{C}$; deionized water pressure $=$ $20 \mathrm{MPa}$ ). The specimens are cured using layers to observe the changes in cement under different environments and after a different number of days (Fig. 2).

\section{EXPERIMENTAL RESULTS}

\subsection{Supersonic Detection}

A dry-point type low-frequency supersonic probe is used to measure the time and speed of the longitudinal and transverse supersonic cement waves after the reaction (Figs. 3a - b). Figure 3a shows that the speed of the longitudinal and transverse specimen waves exhibit no apparent change after different numbers of curing days under the supercritical $\mathrm{CO}_{2}$ layer. Figure $3 \mathrm{~b}$ illustrates that according to supersonic detection the specimens cured under the supercritical $\mathrm{CO}_{2}$ with water layer exhibit declining longitudinal and transverse wave speed during the first set of days (0 - 14 days), whereas the rebounding speed is observed at the late stage (14 - 84 days).

\subsubsection{Theoretical Explanation for the Result of Supersonic Detection}

The basic theory proposed by Jones for supersonic transmission in concrete is shown below (Jones 1962):

$V_{p}=\sqrt{\frac{E_{d}(1-v)}{\rho(1+v)(1-2 v)}}$

$V_{s}=\sqrt{\frac{E_{d}}{\rho} \frac{1}{2(1+v)}}$

$V_{\mathrm{p}}$ and $V_{\mathrm{s}}$ represent the longitudinal and transverse speeds of the supersonic waves transmitted in the specimen, respectively. $E_{d}=$ dynamic Young's modulus; $\rho=$ specimen density; $v=$ Poisson's ratio. The following equation is obtained in combination with Eqs. (1) and (2):

$v=\frac{V_{p}^{2} / 2-V_{s}^{2}}{V_{p}^{2}-V_{s}^{2}}$

\section{1 .2 Poisson's Ratio and Dynamic Young's Modulus Coefficient}

Supersonic waves are used to detect the longitudinal and transverse waves of the cured specimens. The parameter obtained is incorporated into Eq. (3) to determine the change in the Poisson's ratio of the specimens after different numbers of curing days (Fig. 4). The Poisson's ratio of the specimens shows a rising trend under different numbers of curing days and varied curing environments. The changes are clearly observable at the supercritical $\mathrm{CO}_{2}$ with water layer.

The Poisson's ratio of the specimen obtained and specimen density after different numbers of reaction days are incorporated into Eq. (1) to calculate the dynamic elasticity coefficient of the specimens (Fig. 5). Figure 5 shows that the dynamic Young's modulus of the specimens after different numbers of curing days and under varied curing environments exhibits a rising trend. The dynamic elasticity coefficient at the supercritical $\mathrm{CO}_{2}$ with water layer shows apparent changes.

\subsubsection{Damage Factor}

According to the elasticity rule for damaged materials proposed by Budiansky and O'connell (1976), material defects resulting from damage caused by the external environment can be defined by the damage factor $\mathrm{D}$, as follows:

$\mathrm{D}=1-\frac{\tilde{\mathrm{E}}}{\mathrm{E}}$

$\widetilde{E}:$ The Young's modulus after damage;

E: The original Young's modulus.

The dynamic Young's modulus of the uncured specimens and that of the specimens cured at different numbers of days are incorporated into Eq. (4) to obtain the extent of damage sustained by the specimens after different numbers of curing days (Fig. 6). Figure 6 shows that the extent of damage sustained by the specimens cured under the $\mathrm{CO}_{2}$ with water layer is greater than that sustained by the specimens cured under the supercritical $\mathrm{CO}_{2}$ layer.

\subsection{Uniaxial Compressive Strength}

The uniaxial comprehensive strength of the specimens cured at different numbers of days in the $\mathrm{CO}_{2}$ reactor is depicted in Fig. 7. The uniaxial comprehensive strength of the specimens cured in the supercritical $\mathrm{CO}_{2}$ environment for 84 days decreases by $34 \%$ and that of the specimens cured under the supercritical $\mathrm{CO}_{2}$ with water environment for 84 days is reduced by about $78 \%$. 


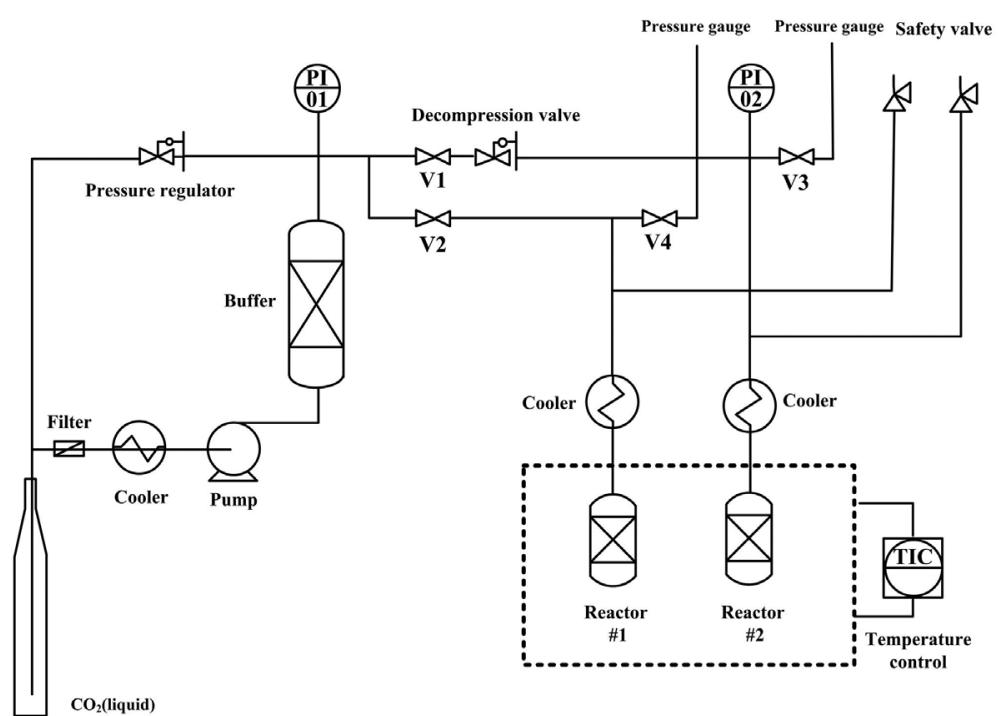

Fig. 1. Experimental layout of the supercritical reactor.

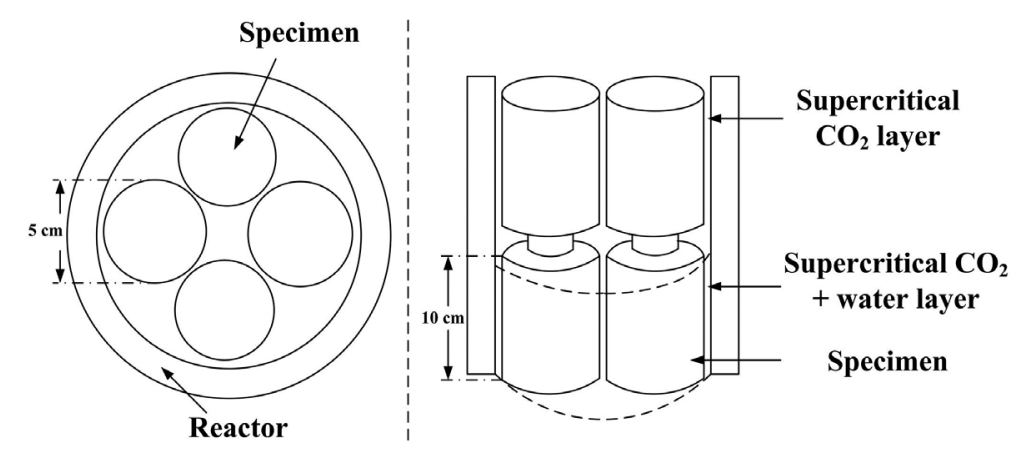

Fig. 2. Placement of curing specimens.

(a)

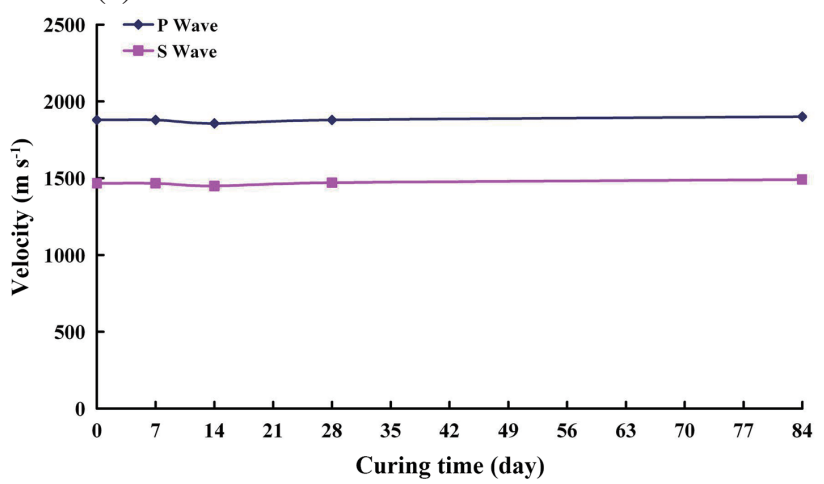

(b) Environment (Supercritical $\mathrm{CO}_{2}+$ Water layer)

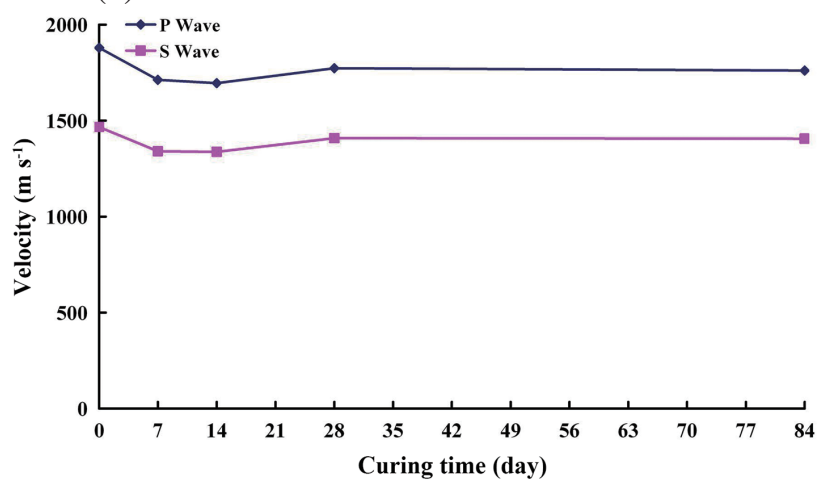

Fig. 3. The specimens speed of the longitudinal and transverse waves; (a) supercritical $\mathrm{CO}_{2}$ layer (b) supercritical $\mathrm{CO}_{2}$ with water layer. (Color online only) 


\section{Dynamic Poisson's ratio}

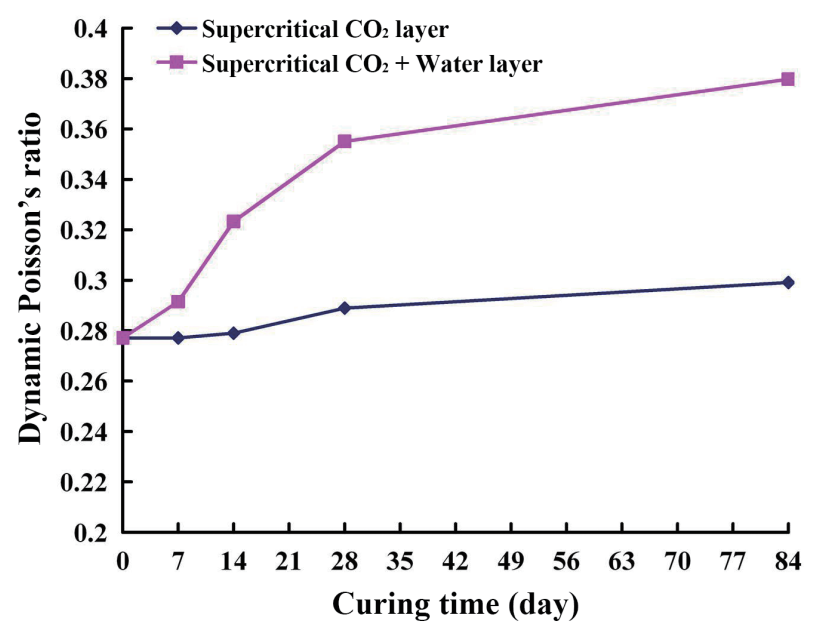

Fig. 4. Dynamic Poisson's ratio. (Color online only)

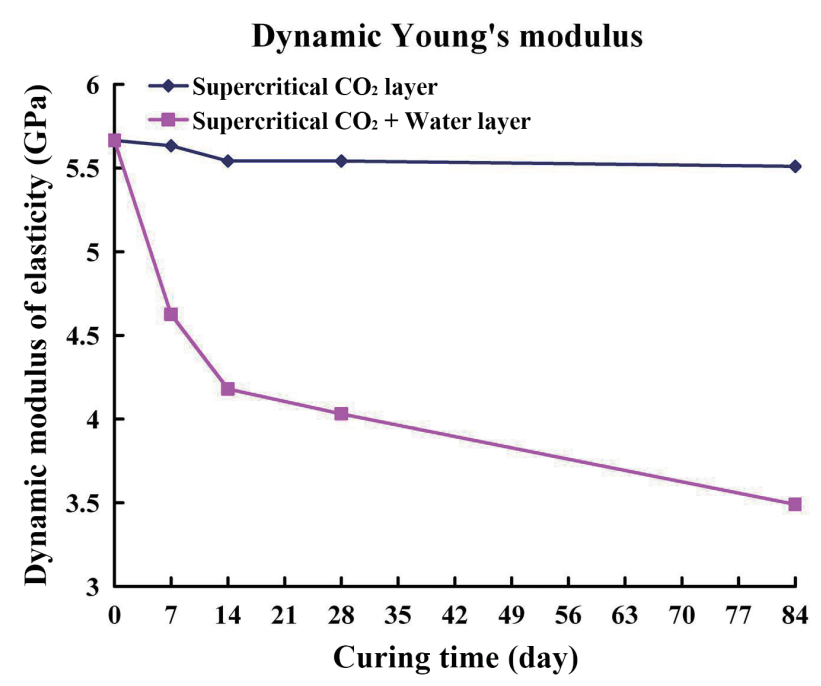

Fig. 5. Dynamic Young's modulus. (Color online only)

\section{Damage Factor}

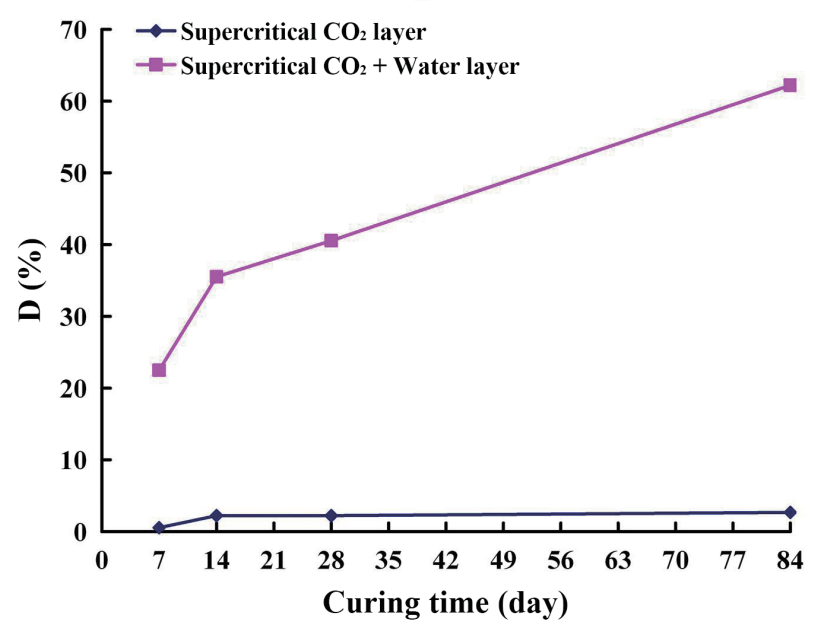

Fig. 6. The Damage factor versus curing time. (Color online only)

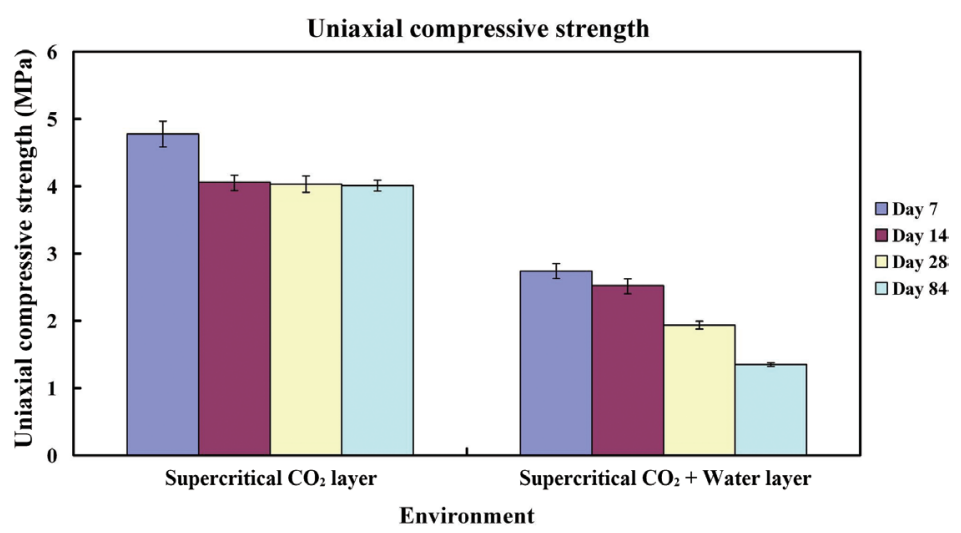

Fig. 7. Uniaxial compressive strengths of specimens under different environments. 


\subsection{Polarizing Microscopy}

The carbonization depth of the specimen after different curing days ( 7 - 84 days) is shown in Table 1, which also illustrates that the carbonization region of the specimens exhibits a deepening trend along with the increase in the number of curing days. The carbonization depth under the supercritical $\mathrm{CO}_{2}$ with water layer is the largest (curing for 84 days $=9.04 \mathrm{~mm}$ ). Figure 8 shows the polarizing microscopy result for the specimens cured under the supercritical $\mathrm{CO}_{2}$ with water layer for 84 days.

\subsection{X-Ray Powder Diffraction Analysis}

The XRD (X-Ray Diffraction) analysis result for the surfaces of the cured specimens is shown in Figs. 9a - b. The major components of API G-level cement are carbon hydroxide $\left[\mathrm{Ca}(\mathrm{OH})_{2}\right]$, water and calcium silicate $(\mathrm{C}-\mathrm{S}-\mathrm{H})$. Based on Fig. 9 we can conclude that the reaction zone shows carbonization with increasing curing period, which results in two polytypes of calcium carbonate $\left(\mathrm{CaCO}_{3}\right)$ : calcite and aragonite. According to Kutchko et al. (2007), the reaction behavior of calcium carbonation in cement is defined as follows.

$$
\begin{aligned}
& \mathrm{CO}_{2(\text { aq })}+\mathrm{H}_{2} \mathrm{O} \rightarrow \mathrm{H}_{2} \mathrm{CO}_{3(\text { aq })} \rightarrow \mathrm{H}^{+}{ }_{(\mathrm{aq})}+\mathrm{HCO}_{3 \text { (aq) }}^{-} \\
& \mathrm{Ca}(\mathrm{OH})_{2(\mathrm{~s})} \rightarrow \mathrm{Ca}^{2+}{ }_{(\mathrm{aq})}+2 \mathrm{OH}^{-}{ }_{(\mathrm{aq})} \\
& \mathrm{Ca}^{2+}{ }_{(\mathrm{aq})}+\mathrm{HCO}_{3(\mathrm{aq})}^{-}+\mathrm{OH}^{-}{ }_{\text {(aq) }} \rightarrow \mathrm{CaCO}_{3(\mathrm{~s})}+\mathrm{H}_{2} \mathrm{O} \\
& \mathrm{C}-\mathrm{S}-\mathrm{H}_{(\mathrm{s})}+\mathrm{H}^{+}+\mathrm{HCO}_{3(\text { (aq) }}^{-} \rightarrow \mathrm{CaCO}_{3(\mathrm{~s})}+\mathrm{SiO}_{2(\mathrm{~s})}+\mathrm{H}_{2} \mathrm{O}
\end{aligned}
$$

When cement is under continuous leaching by carbonic acid; $\mathrm{Ca}(\mathrm{OH})_{2}$ and C-S-H are converted into $\mathrm{CaCO}_{3}$ and non-cementing $\mathrm{SiO}_{2}$, thereby reducing cement alkalinity and damaging the structure.

\subsection{Ingredient Analysis}

The changes in the chemical compositions of the cured specimens are measured by EDS (Energy Dispersive Spectrometer) at a sampling interval of $60 \mathrm{~s}$ to ensure high sampling rate during the detection. The results are shown in Figs. 10a - c. The figure shows that trace atoms such as $\mathrm{Mg}$, $\mathrm{K}$, and $\mathrm{Al}$ are detected after different curing periods. This figure also compares the compositions at the surface and

Table 1. Carbonation depth.

\begin{tabular}{ccc}
\hline Carbonation depth & Supercritical $\mathbf{C O}_{2}$ layer & Supercritical $\mathbf{C O}_{2}+$ Water layer \\
\hline Reaction Day 7 & $0.09 \mathrm{~mm}$ & $0.26 \mathrm{~mm}$ \\
Reaction Day 14 & $0.90 \mathrm{~mm}$ & $2.21 \mathrm{~mm}$ \\
Reaction Day 28 & $2.22 \mathrm{~mm}$ & $4.43 \mathrm{~mm}$ \\
Reaction Day 84 & $3.60 \mathrm{~mm}$ & $9.04 \mathrm{~mm}$ \\
\hline
\end{tabular}

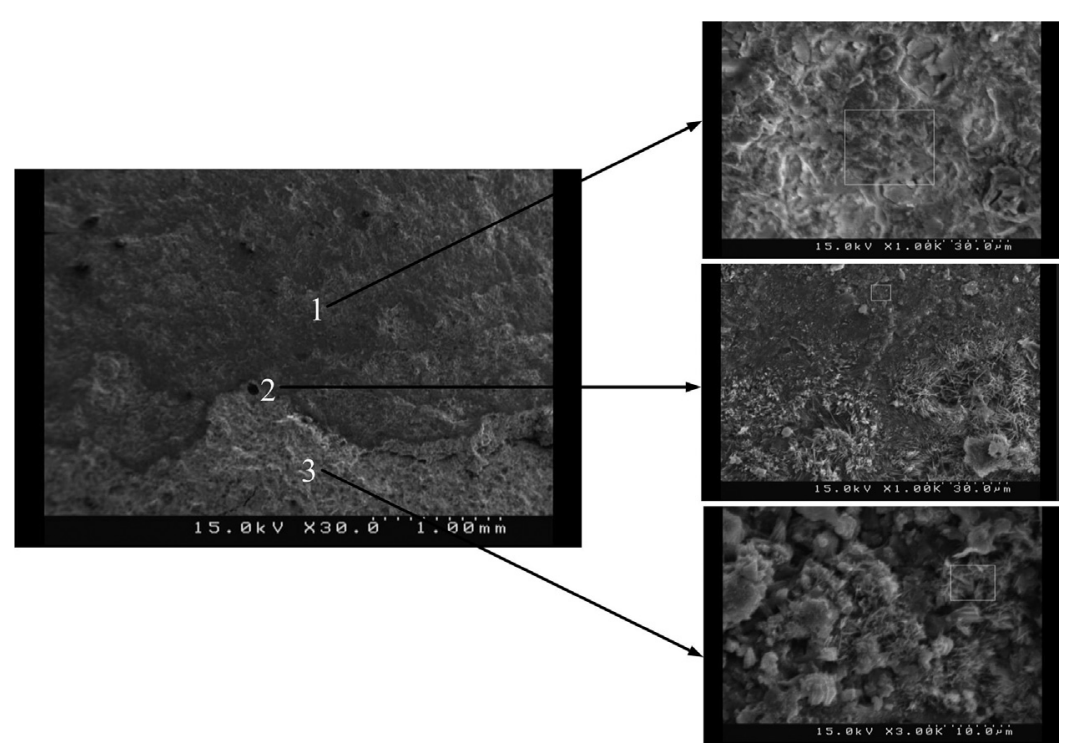

Fig. 8. SEM (supercritical $\mathrm{CO}_{2}$ with water layer, Reaction Day 84). 

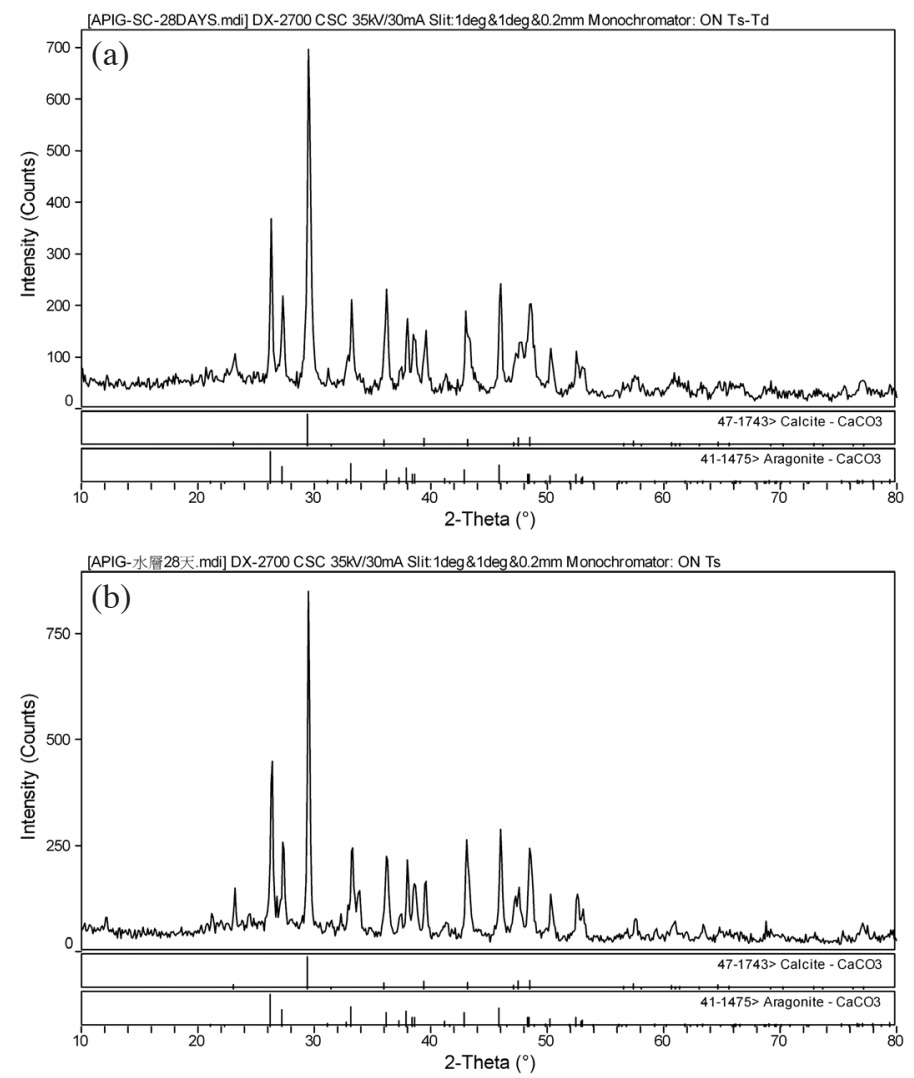

Fig. 9. XRD (Reaction Day 84); (a) supercritical $\mathrm{CO}_{2}$ layer (b) supercritical $\mathrm{CO}_{2}$ with water layer.

(a)

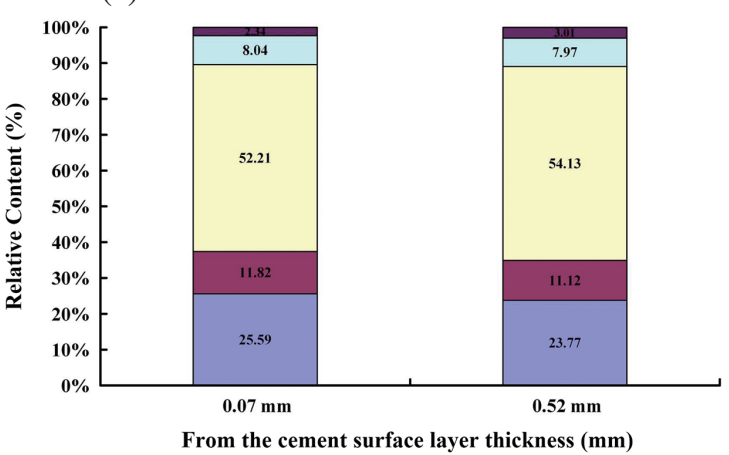

(c) $\quad$ EDS (Supercritical $\mathrm{CO}_{2}$ with Water layer)

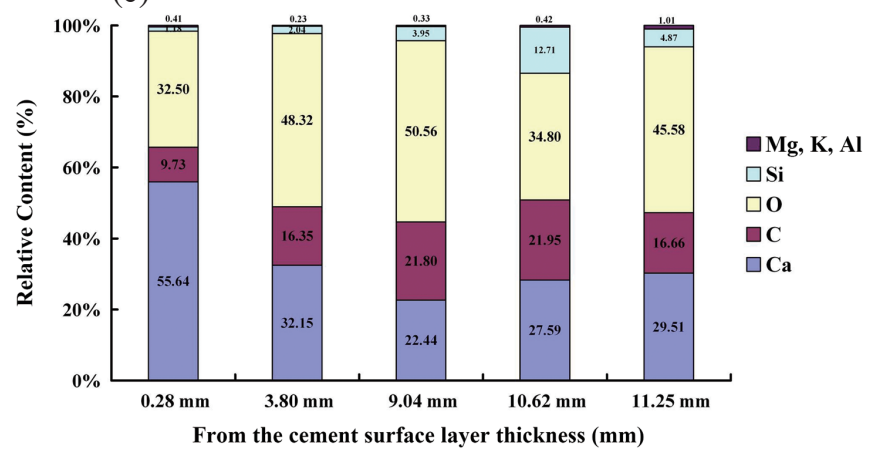

Fig. 10. EDS (Reaction Day 84 of specimen under different environments); (a) before reaction specimens, (b) supercritical $\mathrm{CO}_{2}$ layer, (c) supercritical $\mathrm{CO}_{2}$ with water layer. (b) $\quad$ EDS (Supercritical $\mathrm{CO}_{2}$ layer)

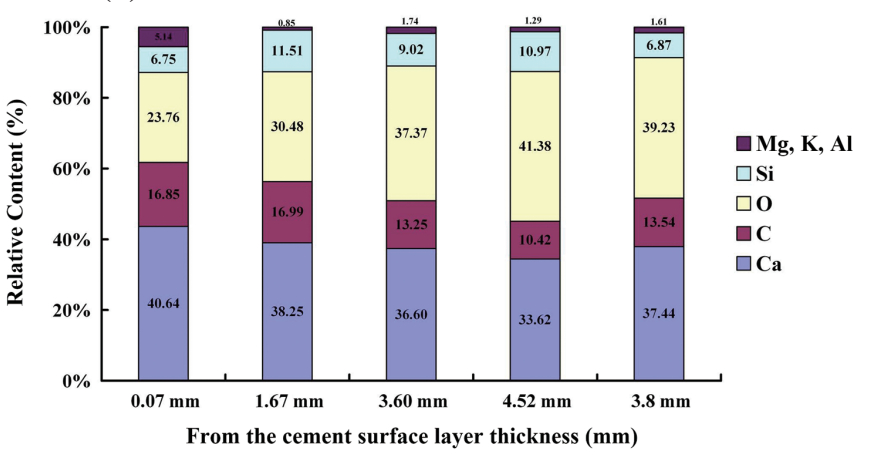


lower layer of the specimens cured for 28 days.

We can conclude from the uncured API specimens shown in Fig. 10a that the specimen chemical compositions exhibit no apparent changes at different cement surface layer depths. The ingredient analysis of specimens cured for 28 days under the supercritical $\mathrm{CO}_{2}$ layer shows that that the relative percentage of $\mathrm{Ca}$ and $\mathrm{Si}$ at $1.67 \mathrm{~mm}$ from the surface is higher than that of the uncured specimens. We can deduce that the $\mathrm{Ca}(\mathrm{OH})_{2}$ and $\mathrm{C}-\mathrm{S}-\mathrm{H}$ in the cement are converted into $\mathrm{CaCO}_{3}$ and non-cementing $\mathrm{SiO}_{2}$ when leached by carbonic acid. This conversion reduces the cement alkalinity and damages the structure.

As indicated by the composition analysis of specimens cured for 28 days under the supercritical $\mathrm{CO}_{2}$ with water layer (Fig. 10c), the carbonation effect at $4.23 \mathrm{~mm}$ from the surface is obviously reduced, which in turn, decreases cement alkalinity and damages the structure.

\section{CONCLUSION}

A curing experiment on API G-level cement was conducted in this study under a supercritical $\mathrm{CO}_{2}$ environment (temperature $=70^{\circ} \mathrm{C}$; pressure $=20 \mathrm{MPa}$ ) in a supercritical $\mathrm{CO}_{2}$ reactor for different curing periods. The results are summarized as follows.

(1) The supersonic experiment result indicates that the longitudinal and transverse waves of specimens cured under the $\mathrm{CO}_{2}$ environment exhibit a declining trend at the early curing stage ( 0 - 14 days), but a rebounding trend at the late stage (14 - 84 days) as the curing periods increase. The Poisson's ratio of the specimens drops and the dynamic Young's modulus increases with increasing number of days.

(2) As the number of curing days increases, $\mathrm{Ca}(\mathrm{OH})_{2}$ and $\mathrm{C}$ $\mathrm{S}-\mathrm{H}$ are converted into $\mathrm{CaCO}_{3}$ and non-cementing $\mathrm{SiO}_{2}$ when the specimen is continuously leached by carbonic acid. This conversion reduces cement alkalinity and damages the structure.

(3) The extent of damage sustained by the specimens cured in the supercritical $\mathrm{CO}_{2}$ with water layer is greater than that sustained by the specimens cured in the supercritical $\mathrm{CO}_{2}$ layer as the curing period increases. The uniaxial compressive strength is reduced by about $78 \%$. Water is the major factor that caused cement specimen carbonization in this study.

\section{REFERENCES}

American Petroleum Institute (API), 1985: API Recommended Practice for Testing Well Cements, API Recommended Practice 10B, Washington DC, 115-163.

Barlet-Gouédard, V., G. Rimmelé, B. Goffé, and O. Porcherie, 2007: Well Technologies for $\mathrm{CO}_{2}$ Geological Stor- age: $\mathrm{CO}_{2}$-Resistant Cement. Oil \& Gas Science and Technology, 62, 325-334, doi: 10.2516/ogst:2007027. [Link]

Benge, G., 2009: Improving wellbore seal integrity in $\mathrm{CO}_{2}$ injection wells. Energy Procedia, 1, 3523-3529, doi: 10.1016/j.egypro.2009.02.145. [Link]

Budiansky, B. and R. J. O'connell, 1976: Elastic moduli of a cracked solid. Int. J. Solid. Struct., 12, 81-97, doi: 10.1016/0020-7683(76)90044-5. [Link]

Carey, J., J. Wigand, S. Chipera, S. WoldeGabriel, S. Pawar, P. Lichtner, S. Wehner, M. Raines, and G. Guthrie, 2007: Analysis and performance of oil well cement with 30 years of $\mathrm{CO}_{2}$ exposure from the SACROC Unit, West Texas, USA. Int. J. Greenh. Gas Con., 1, 75-85, doi: 10.1016/S1750-5836(06)00004-1. [Link]

Fabbri, A., J. Corvisier, A. Schubnel, F. Brunet, B. Goffé, G. Rimmele, and V. Barlet-Gouédard, 2009: Effect of carbonation on the hydro-mechanical properties of Portland cements. Cement Concr. Res., 39, 1156-1163, doi: 10.1016/j.cemconres.2009.07.028. [Link]

Gislason, S. R., R. Wolff-Boenisch, R. Stefansson, E. Oelkers, E. Gunnlaugsson, E. Sigurdardottir, E. Sigfusson, W. Broecker, J. Matter, and J. Stute, 2010: Mineral sequestration of carbon dioxide in basalt: A pre-injection overview of the CarbFix project. Int. J. Greenh. Gas Con., 4, 537-545, doi: 10.1016/j.ijggc.2009.11.013. [Link]

Iding, M. and P. Ringrose, 2010: Evaluating the impact of fractures on the performance of the In Salah $\mathrm{CO}_{2}$ storage site. Int. J. Greenh. Gas Con., 4, 242-248, doi: 10.1016/j.ijggc.2009.10.016. [Link]

Jones, R., 1962: Non-destructive Testing of Concrete, Cambridge University Press, London, 162-190.

Kutchko, B., B. Strazisar, D. Dzombak, G. Lowry, and G. Thaulow, 2007: Degradation of Well Cement by $\mathrm{CO}_{2}$ under Geologic Sequestration Conditions. Environ. Sci. Technol., 41, 4787-4792, doi: 10.1021/es062828c. [Link]

Liteanu, E., C. J. Spiers, and C. J. Peach, 2009: Failure behaviour wellbore cement in the presence of water and supercritical $\mathrm{CO}_{2}$. Energy Procedia, 1, 3553-3560, doi: 10.1016/j.egypro.2009.02.149. [Link]

Rimmelé, G., V. Barlet-Gouédard, O. Porcherie, B. Goffé, and F. Brunet, 2008: Heterogeneous porosity distribution in Portland cement exposed to $\mathrm{CO}_{2}$-rich fluids. Cement Concr. Res., 38, 1038-1048, doi: 10.1016/j. cemconres.2008.03.022. [Link]

Viswanathan, H., R. Pawar, P. Stauffer, J. Kaszuba, J. Carey, S. Olsen, G. Keating, G. Kavetski, and G. Guthrie, 2008: Development of a Hybrid Process and System Model for the Assessment of Wellbore Leakage at a Geologic $\mathrm{CO}_{2}$ Sequestration Site. Environ. Sci. Technol., 42, 7280-7286, doi: 10.1021/es800417x. [Link]

Wigand, M., J. P. Kaszuba, J. W. Carey, and W. K. 
Hollis, 2009: Geochemical effects of $\mathrm{CO}_{2}$ sequestration on fractured wellbore cement at the cement/caprock interface. Chem. Geol., 265, 122-133, doi: 10.1016/j. chemgeo.2009.04.008. [Link] 